\title{
Aortic remodeling in Type $B$ aortic dissection after thoracic endovascular aortic repair with an aortic extender cuff implantation
}

This article was published in the following Dove Press journal:

Clinical Interventions in Aging

\author{
Honggang Zhang ' \\ Tong Qiao ${ }^{2}$
}

'Department of Vascular Surgery, Lianyungang Clinical College of Nanjing Medical University, Lianyungang 222000, Jiangsu, China; ${ }^{2}$ Department of Vascular Surgery, Gulou Clinical College of Nanjing Medical University, Nanjing 210000 , Jiangsu, China
Correspondence: Tong Qiao Department of Vascular Surgery, Gulou Clinical College of Nanjing Medical University, No 32I, Zhongshan Road, Nanjing 210000, Jiangsu, China Email qiaotong@nju.edu.cn
Objective: This study investigated the safety and efficiency of thoracic endovascular aortic repair (TEVAR) plus an aortic extender cuff placement in treating Stanford Type B aortic dissections (TBADs).

Methods: Clinical data on 157 patients with TBADs who underwent TEVAR in two tertiary medical centers from February 2013 to March 2018 were analyzed retrospectively. An estimated mismatch rate $>120 \%$ was the indication for placement of an aortic extender cuff. Results in the perioperative and follow-up periods ( $\geq 3$ months) were analyzed, especially those of aortic remodeling.

Results: In total, 106 patients (67.5\%) underwent standard TEVAR, and 51 (32.5\%) received TEVAR plus an aortic extender cuff placement. The primary technical success rate was $96.8 \%$ (152/157). Perioperative adverse events included endoleak $(2 \%, 3 / 157)$, spinal cord ischemia (SCI) $(1.3 \%, 2 / 157)$, and transient renal failure $(0.6 \%, 1 / 157)$, with no between-group differences. The median follow-up was 15 months (range 3-71 months). Ten cases of late stent complications were observed, including three endoleak, one upper limb ischemia, one stent distortion, and five stent graft-induced distal re-dissection (SIDR). Patients with a cuff had less distal re-dissection and fewer second interventions, but the differences lacked significance. In the last follow-up, the TEVAR+Cuff group were found to have better true lumen recovery and false lumen shrinkage, and increased complete false lumen thrombosis in the thoracic and abdominal segments; however, no statistical difference was evident in comparison with the TEVAR group $(P>0.05)$.

Conclusion: TEVAR plus an aortic extender cuff implantation improves remodeling of the dissected thoracic aorta, thus reducing the potential of SIDR. Furthermore, the covered stent with a length of $250 \mathrm{~mm}$ does not increase the rate of SCI or paraplegia. However, these results should be confirmed in a larger series of patients with longer follow-up.

Keywords: Type B aortic dissection, thoracic endovascular aortic repair, aortic extender cuff, aortic remodeling

\section{Introduction}

Aortic dissection is the most common fatal condition that involves the aorta. ${ }^{1}$ The best therapy for uncomplicated acute Type B aortic dissection is medical treatment, and surgical repair is only reserved for complicated dissections, such as rupture, ischemia of vital organs, progression of the dissection, and uncontrollable arterial hypertension. However, with its mortality and morbidity remaining significant from $6 \%$ to $67 \%{ }^{2}$ surgery has been gradually displaced by endovascular techniques. ${ }^{3}$

Since it was first described by Dake et al and Nienaber et al in 1999, thoracic endovascular aortic repair (TEVAR) has been developed as a safe and effective treatment 
for Stanford Type B aortic dissections (TBADs). ${ }^{4,5}$ Several reports and meta-analyses have demonstrated the efficacy of TEVAR, with significantly less peri-procedural mortality and complications and favorable short-term and midterm outcomes. ${ }^{6,7}$ Furthermore, in 2014, stent graft repair was recommended as a Class I treatment for complicated Type B dissections by the European Society of Cardiology Guidelines. ${ }^{8}$ Despite the demonstrated lower morbidity and mortality associated with TEVAR in comparison with conventional surgery, many publications reported various stent-graft-related complications, such as retrograde Type A dissection, endoleak, stent migration or fracture, and stent-graft-induced distal redissections (SIDRs). ${ }^{9,10}$ As an infrequent complication but one that is associated with a high mortality rate, SIDR has drawn growing attention in these years. The mismatch between the size of the distal stent graft and the fairly narrow true lumen (TL), which was compressed by the false lumen (FL), may contribute to the occurrence of SIDR. ${ }^{11,12}$ One potential solution is to use the distal restrictive bare stent (RBS) to prevent this mismatch. Several studies with a large sample size have documented that TEVAR+RBS could improve early aortic remodeling and reduce the incidence of SIDR. ${ }^{13,14}$ However, research on aortic remodeling after TEVAR+Cuff are still scarce. In this study, we inserted an Endurant aortic extender cuff into the intended distal part of the aorta with the proper size, prior to the introduction of the main aortic stent graft. Using this technique for the management of Stanford TBADs, we aimed to help fill the research gap by evaluating clinical outcomes, especially with regard to aortic remodeling.

\section{Methods}

\section{Data collection and follow-up}

Our retrospective study was approved by the institutional review boards of two institutions - Lianyungang Clinical College and Gulou Clinical College of Nanjing Medical University. Written informed consent, in accordance with the principles of the Declaration of Helsinki, was obtained from each patient involved in this study. From February 2013 to March 2018, 157 patients with TBADs underwent TEVAR in the two medical centers. All the patients were diagnosed with TBADs by the computed tomography angiography (CTA) images. These patients were considered unsuitable or unwilling for open surgery, and all agreed to undergo TEVAR. The indication for the use of the distal aortic extender cuff was an estimated mismatch rate (ratio of distal diameter of stent graft to long diameter of TL) $>120 \%$. Under this protocol, the 157 patients were divided into two groups: 106 underwent standard TEVAR (TEVAR group) and 51 were treated with TEVAR and cuff implantation (TEVAR+Cuff group).
Clinical data included operative details, technical success, as well as adverse events occurring during hospitalization and follow-up, such as endoleak, retrograde dissection, rupture, stroke, and re-intervention. Images of aorta CTA, physical examination, and laboratory tests taken before the operation and during the follow-up were collected and analyzed.

\section{Endovascular procedures}

The landing-zone diameters, region, and stent-graft dimensions were calculated from preoperative CTA images. All procedures were conducted under general anesthesia in the interventional radiology suite. After femoral artery exposure and aortography were done to confirm the preoperative measurements, we chose the size of aortic extender cuff suitable for the distal end of the main aortic stent graft, with no oversizing. The cuff was placed into the targeted position, intended to provide a $30-40 \mathrm{~mm}$ overlapping zone for the main stent graft. The size of the main stent graft was chosen according to the measurements of the proximal nondissected aorta, with an oversizing of $0-15 \%$. A complete aortic angiogram was conducted to examine the immediate results. Additional procedures, such as left subclavian artery (LSA) coverage, the chimney technique, or balloon dilatation, was carried out when necessary. Primary technical success was defined as complete exclusion of the primary tear site and absence of any immediate complication.

\section{Assessment of aortic remodeling}

The CTA was planned at 3 months, 6 months, and annually after the operation. The measurements of the aorta included diameters of TL, FL, and the whole aorta at the LSA ostium level (Level A), tracheal carina level (Level B), diaphragmatic level (Level C), and level of the celiac trunk (Level D) (Figure 1). Axial image data were transferred to a workstation and analyzed with OsiriX (Version 8.0.1; OsiriX Foundation, Geneva, Switzerland). All measurements were calculated by two experienced technicians independently, and the mean values were used for the outcome analyses.

\section{Statistical analysis}

SPSS 21 (SPSS, Inc., Chicago, IL, USA) was used for statistical analysis. Descriptive statistics were summarized as means $\pm \mathrm{SD}$, medians, and ranges for the continuous variables. Categorical variables were presented as numbers and proportions, and analyzed using chi-square or Fisher's exact tests, as appropriate. Continuous variables between groups were compared using the two-tailed $t$-tests. A $P$-value $<0.05$ was considered significant. 


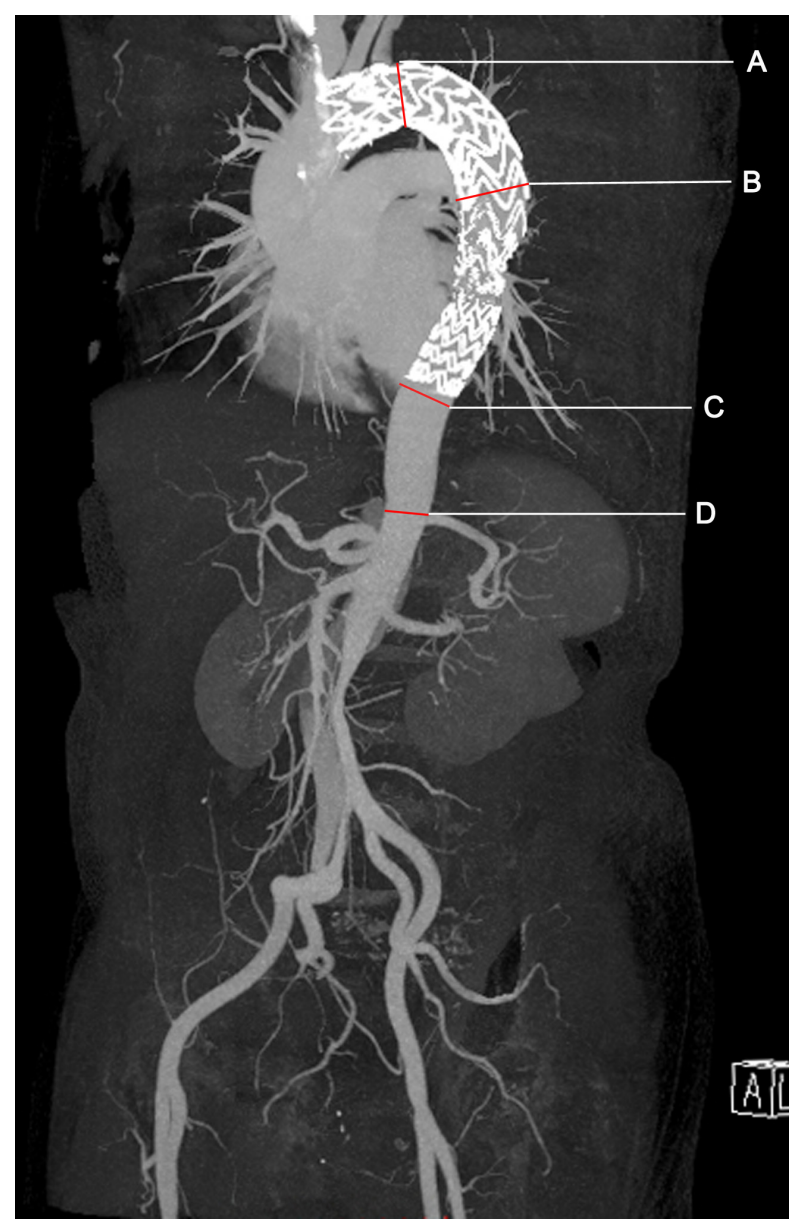

Figure I The measurements were taken at four levels.

Notes: Level A: LSA ostium level; Level B: the tracheal carina level; Level C: the diaphragmatic level; and Level $D$ : the level of the celiac trunk.

Abbreviation: LSA, left subclavian artery.

\section{Results}

\section{Patient characteristics}

The average age of the 157 patients - 133 males (84.7\%) and 24 females $(15.3 \%)$ - was $64.9 \pm 7.1$ years. Thirty-eight patients were operated in the acute phase $(24.2 \%),{ }^{9} 108$ in the subacute phase (68.8\%), and 11 in the chronic phase (7.0\%). In total, 106 patients $(67.5 \%)$ were primarily subjected to standard TEVAR, and 51 cases $(32.5 \%)$ underwent TEVAR+Cuff. The detailed patient characteristics of the two groups had no statistical difference (Table 1). Four main aortic stent-graft systems were used in this study: Ankula (38/157, 24.2\%; Lifetech Scientific, Shenzhen, China); Hercules (28/157, 17.8\%; Microport, Shanghai, China); Valiant (70/157, 44.6\%; Medtronic Endovascular System, Santa Rosa, CA, USA), and the Castor Branched Aortic Stent Graft System (21/157, 13.4\%; Microport Medical, Shanghai, China). An aortic extender cuff $24-28 \mathrm{~mm}$ in diameter by 60-80 mm in length (Endurant, Medtronic Cardiovascular, Santa Rosa, CA, USA) was selected. No death occurred during the perioperative period in both groups. The perioperative adverse events included endoleak $(2 \%, 3 / 157)$, transient renal failure $(0.6 \%, 1 / 157)$, and spinal cord ischemia (SCI; $1.3 \%, 2 / 157)$. Endoleak was present in three cases and was considered not significant; therefore, the patients were taken up for observation. Transient renal failure in a patient with a history of renal insufficiency was cured before discharge. The two cases with transient SCI recovered in a few days after treatment with vasopressors and neurotrophic drugs.

Table I Patient characteristics

\begin{tabular}{|c|c|c|c|}
\hline Variables & $\begin{array}{l}\text { TEVAR group } \\
\text { no }(\%) \text { or mean } \pm \text { SD }\end{array}$ & $\begin{array}{l}\text { TEVAR+Cuff group } \\
\text { no (\%) or mean } \pm \text { SD }\end{array}$ & $P$-value \\
\hline Patient total & 106 & 51 & \\
\hline Age, in years & $65.7 \pm 12.4$ & $63.3 \pm 11.2$ & $>0.05$ \\
\hline \multicolumn{4}{|l|}{ Sex } \\
\hline Male & $91(85.8)$ & $42(82.4)$ & $>0.05$ \\
\hline Female & $15(14.2)$ & $9(17.6)$ & \\
\hline Hypertension & $75(70.8)$ & $39(76.5)$ & $>0.05$ \\
\hline Diabetes & $3(2.8)$ & I (2.0) & $>0.05$ \\
\hline CAD & $3(2.8)$ & $2(3.9)$ & $>0.05$ \\
\hline COPD & $7(6.7)$ & $3(5.9)$ & $>0.05$ \\
\hline Renal insufficiency & $3(2.8)$ & I (2.0) & $>0.05$ \\
\hline Previous CVA & $5(4.7)$ & $2(3.9)$ & $>0.05$ \\
\hline Previous aortic repair & $5(4.7)$ & $2(3.9)$ & $>0.05$ \\
\hline Tobacco abuse & $26(24.5)$ & II (2I.6) & $>0.05$ \\
\hline \multicolumn{4}{|l|}{ Phase of TBADs } \\
\hline Acute/subacute/chronic & $28 / 70 / 8$ & $10 / 38 / 3$ & $>0.05$ \\
\hline
\end{tabular}

Abbreviations: CAD, coronary artery disease; CVA, cerebrovascular accident; TBADs, Stanford Type B aortic dissections; TEVAR, thoracic endovascular aortic repair. 
No stroke or persistent paraplegia was found during the perioperative period.

\section{Follow-up}

The median follow-up was 15 months, with a range of 3-71 months. Fifty-one cuffs were used with a median size of $24 \mathrm{~mm}$ (range 20-28 mm). The overlapping length between the cuff and the main aortic stent graft was $37.5 \pm 3.4 \mathrm{~mm}$. One case of cuff distortion was found on CTA 4 years after operation and, then, a second intervention was undertaken in this patient (Figure 2). No other dislocation or fracture of the cuff was observed during follow-up. The occurrence of SIDR was lower in the TEVAR+Cuff group (2.0\% vs $3.8 \%, P>0.05)$, and a decrease in the second intervention rate was observed in this group as well; however, both were not significant as compared with the TEVAR group. One patient with upper limb ischemia and three with endoleak were detected in the follow-up, two of whom underwent re-intervention because the endoleak was obvious. More detailed operation data is given in Table 2.

\section{Aortic remodeling}

As shown in Figures 3 and 4, the TLs at levels A, B, and $\mathrm{C}$ were significantly expanded in both groups. Simultaneously, the FLs at levels A, B, and C significantly decreased in the last follow-up. Although the TLs and FLs changed significantly at different levels in both groups, especially in the thoracic segment, no significant difference was found between the TEVAR group and the TEVAR+Cuff group. Table 3 compares the whole aortic morphological changes between the two groups. As seen in this table, the diametric changes of the whole aorta at the four levels were quite small in both groups, and the difference between the two groups at each level was not significant. As shown in Table 4, in the thoracic segment, the complete thrombosis rate was $85 \%(85 / 100)$ in the TEVAR group and $88.9 \%(40 / 45)$ in the TEVAR+Cuff group. In the abdominal segment, the complete thrombosis rate was $20.5 \%(8 / 39)$ in the TEVAR group and $22.7 \%(5 / 22)$ in the TEVAR+Cuff group. The FL thrombosis rate was higher in the TEVAR+Cuff group than in the TEVAR group, but the difference was not significant $(P>0.05)$.

\section{Discussion}

In 1999, the minimally invasive endovascular stent-graft repair was introduced as a novel treatment option for patients with aortic dissection., ${ }^{4,5}$ From then on, many studies had reported TEVAR with encouraging short- and midterm outcomes, and TEVAR has gradually replaced open surgery to become an important optional treatment for complicated
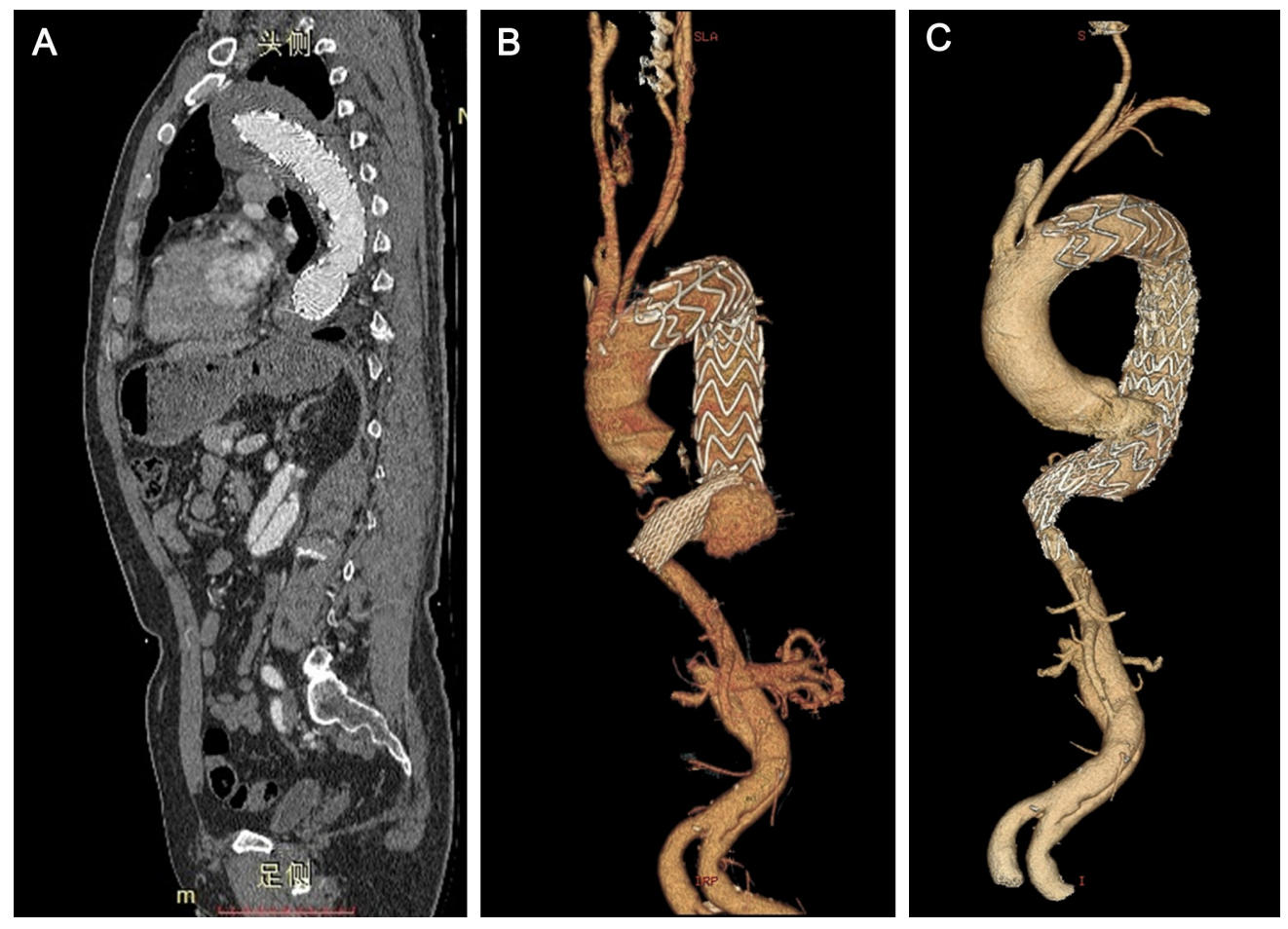

Figure 2 (A) Vertical plane of the patient after the first TEVAR. (B) 3D aorta reconstruction of the patient before the second intervention. (C) 3D aorta reconstruction of the patient 30 days after the second operation.

Abbreviation: TEVAR, thoracic endovascular aortic repair. 
Table 2 Results in perioperative period and follow-up

\begin{tabular}{|c|c|c|c|}
\hline Variables & $\begin{array}{l}\text { TEVAR group } \\
\text { no }(\%) \text { or mean } \pm S D\end{array}$ & $\begin{array}{l}\text { TEVAR+Cuff group } \\
\text { no }(\%) \text { or mean } \pm \text { SD }\end{array}$ & $P$-value \\
\hline Operation time, $\min$ & $139.4 \pm 49.4$ & $|68.4 \pm 6| .3$ & $>0.05$ \\
\hline Emergent/elective operation & $12 / 94$ & $5 / 56$ & $>0.05$ \\
\hline Stent length, mm & $189.5 \pm 26.1$ & $250.3 \pm 38.3$ & $>0.05$ \\
\hline LSA coverage & $28(26.4)$ & $12(23.5)$ & $>0.05$ \\
\hline Technical success & $103(97.1)$ & $49(96.1)$ & $>0.05$ \\
\hline \multicolumn{4}{|l|}{ Complications in operation } \\
\hline Endoleak & $2(1.9)$ & I (2.0) & $>0.05$ \\
\hline Spinal cord ischemia & I (0.9) & I (2.0) & $>0.05$ \\
\hline Renal failure & $I(0.9)$ & 0 & \\
\hline \multicolumn{4}{|l|}{ Follow-up } \\
\hline Median follow-up & 19 , range $3-43$ months & 12 , range $3-7 \mid$ months & \\
\hline \multicolumn{4}{|l|}{ Complications in follow-up } \\
\hline Endoleak & $2(1.9)$ & I (2.0) & $>0.05$ \\
\hline Endograft compression & 0 & I (2.0) & $>0.05$ \\
\hline Upper limb ischemia & I (0.9) & 0 & $>0.05$ \\
\hline Stent graft distortion & 0 & I (2.0) & $>0.05$ \\
\hline
\end{tabular}

Abbreviations: LSA, left subclavian artery; TEVAR, thoracic endovascular aortic repair.

aortic dissections. ${ }^{3}$ However, the long-term durability of stent grafts for dissected aorta remains debatable and stentgraft-induced complications have drawn great attention. Particularly, the reason of distal re-dissection with new entries caused by the stent graft after TEVAR for TBADs has received increasing interest in recent years. ${ }^{15-17}$

SIDR, which was first described by Kato et al ${ }^{18}$ in 2001 as an aneurysmal degeneration of the aorta after TEVAR for acute aortic dissection, is one of the serious and specific complications of TEVAR for aortic dissection. Dong et al reported that the incidence of stent-graft-induced new entry after TEVAR reached $3.4 \%$ in 650 patients, ${ }^{11}$ and the

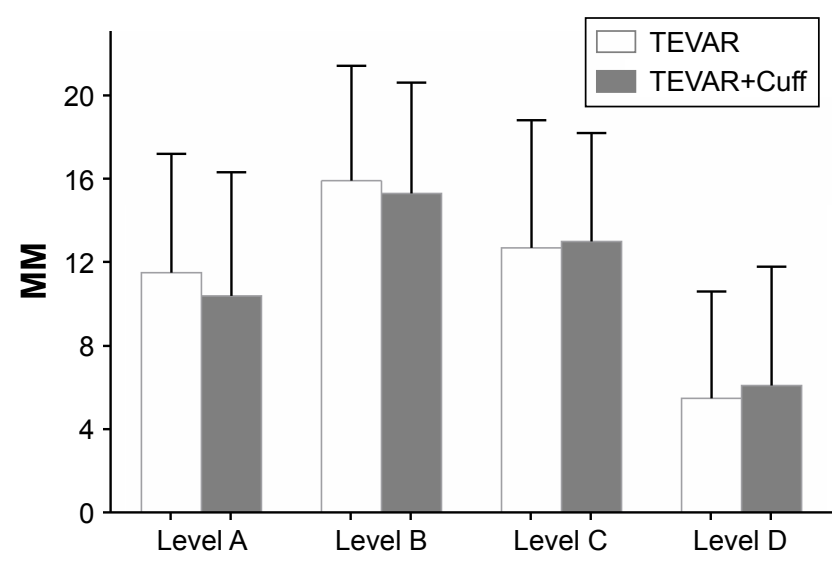

Figure 3 Diametric changes of the true lumen.

Note: No significant difference between the TEVAR group and the TEVAR+Cuff group.

Abbreviation: TEVAR, thoracic endovascular aortic repair. occurrence of SIDR was $1.3 \%-27 \%{ }^{19}$ with a mortality rate of $25 \% .{ }^{11}$ In our cohort, the incidence of SIDR was 3.2\% (5/157), which was equivalent to that in previous reports.

Senf et al and Dong et al thought that excessive oversizing of the distal graft would elevate the radial force at the distal end of the endograft, which could induce a tear. ${ }^{11,20}$ Based on a previous report, which indicated that the use of a restrictive stent could be effective for preventing SIDR, ${ }^{21}$ we believe that the placement of a small-diameter short stent graft at the distal landing zone could act as a protective shield for the fragile dissected aortic wall against the spring-back force.

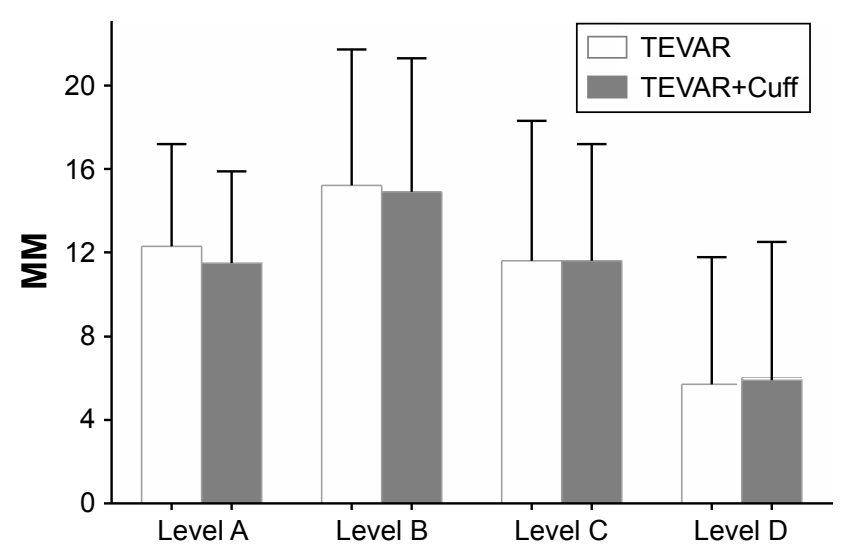

Figure 4 Diametric changes of the false lumen.

Note: No significant difference between the TEVAR group and the TEVAR+Cuff group.

Abbreviation: TEVAR, thoracic endovascular aortic repair. 
Table 3 Diametric changes of the whole aorta at the four levels

\begin{tabular}{|l|l|l|l|}
\hline & $\begin{array}{l}\text { TEVAR } \\
\text { group }(\mathbf{m m})\end{array}$ & $\begin{array}{l}\text { TEVAR+Cuff } \\
\text { group }(\mathbf{m m})\end{array}$ & P-value \\
\hline Level A & $-0.2 \pm 0.8$ & $-0.1 \pm 0.9$ & $>0.05$ \\
\hline Level B & $-0.1 \pm 0.7$ & $0.1 \pm 0.8$ & $>0.05$ \\
\hline Level C & $0.2 \pm 0.5$ & $0.1 \pm 0.6$ & $>0.05$ \\
\hline Level D & $0.2 \pm 0.7$ & $0.1 \pm 0.5$ & $>0.05$ \\
\hline
\end{tabular}

Abbreviation: TEVAR, thoracic endovascular aortic repair.

Several suggestions have been made for preventing SIDR. To minimize the mismatch between the device and the intima, a longer stent graft with better conformability has been recommended. Li et $\mathrm{al}^{22}$ reported that stent-graft coverage $>145 \mathrm{~mm}$ in length could decrease the occurrence of SIDR. To improve the mismatch rate, tapered stent grafts have been designed; for example, Zenith TX2 (COOK, Bjaeverskov, Denmark) and Hercules (Microport, Shanghai, China). However, currently available off-the-shelf tapered devices are limited with regard to matching of proximal and distal sizes, which could not fit the variable dissected aorta, especially in emergency settings. Our study demonstrates that the distal cuff could protect the aortic intima from stent-graftinduced trauma and improve aortic remodeling at thoracic and abdominal segments (although without a statistically significant difference).

SCI and concomitant paraplegia are rare but devastating complications after TEVAR, and the incidence of paraplegia was estimated to be $2.5 \%-8 \%$ in a recent meta-analysis of published studies. ${ }^{23}$ A number of studies have identified various risk factors for SCI in recent years. Ullery et al reported that preoperative renal insufficiency contributed to the incidence of SCI. ${ }^{24}$ Buth et al pointed out that LSA coverage without revascularization and use of three or more stent grafts carry a potential risk for the development of SCI. ${ }^{25}$ Drinkwater et al ${ }^{26}$ revealed that the main risk factor for SCI after endovascular repair was the length of stent coverage of the aorta. Other risk factors for SCI, as described in published reports, include prior aortic repair, perioperative hypotension (mean arterial pressure $<70 \mathrm{mmHg}$ ), COPD, and single-stage procedure..$^{27,28}$ In our study, we consciously avoided these risk factors of SCI. As shown in Tables 1 and 2, there were fewer patients with advanced age, previous aortic repair, COPD, and LSA coverage in the TEVAR+Cuff group $(P>0.05)$. For patients at high risk of SCI, we tended to undertake standard TEVAR; moreover, for patients undergoing TEVAR+Cuff implantation, we intended to shorten the operation time and revascularize the LSA. The results were so good that only one case of SCI occurred in each group and recovered in a few days after treatment with vasopressors and neurotrophic drugs.

Many studies hold that aortic coverage, especially from Th8 to Th12, is associated with an increased risk of SCI..$^{25,29}$ Drinkwater et $\mathrm{al}^{26}$ even suggested that the length of aortic coverage was the most significant risk factor for the development of SCI after TEVAR. In a study by Feezor et al, patients with permanent SCI had a greater absolute length of aortic coverage (260.5 \pm 40.9 vs $195.8 \pm 81.6 \mathrm{~mm}, P=0.002){ }^{30}$ As reported by Amabile et al, endovascular treatment with 205-mm coverage of aorta was a critical length for increased risk of SCI. ${ }^{31}$ Chiesa et al demonstrated that the paraplegia group had an average length of device of $162.7 \pm 26.1 \mathrm{~mm} .{ }^{32}$ In our study, the TEVAR group had a length of device of $189.5 \pm 26.1 \mathrm{~mm}$, and $250.3 \pm 38.3 \mathrm{~mm}$ in the TEVAR+Cuff group $(P<0.05)$. However, no persistent paraplegia was found during the perioperative and follow-up periods, confirming the safety of TEVAR plus cuff technique in treating TBADs. Furthermore, we used an extender cuff instead of distal restrictive bare stent in this study, indicating that longer covered stents with a length of $250 \mathrm{~cm}$ did not increase the incidence of SCI.

In 2011, Nienaber et $\mathrm{al}^{33}$ published the results of their 2-year INSTEAD trial, which provided Level 1 evidence for the treatment of acute uncomplicated TBADs.

Table 4 False lumen thrombosis in the thoracic and abdominal aorta

\begin{tabular}{|l|l|l|l|}
\hline Variables & $\begin{array}{l}\text { TEVAR } \\
\text { group no (\%) }\end{array}$ & $\begin{array}{l}\text { TEVAR+Cuff } \\
\text { group no (\%) }\end{array}$ & P-value \\
\hline False lumen in the thoracic aorta & 100 & 45 & $>0.05$ \\
\hline Patent & $0(0)$ & $0(0)$ & $>0.05$ \\
\hline Partial thrombosis & $15(15)$ & $5(11.1)$ & $>0.05$ \\
\hline Complete thrombosis & $85(85)$ & $40(88.9)$ & 22 \\
\hline False lumen in the abdominal aorta & 39 & $3(13.6)$ & $>0.05$ \\
\hline Patent & $8(20.5)$ & $14(63.6)$ & $>0.05$ \\
\hline Partial thrombosis & $23(59.0)$ & $5(22.7)$ & $>0.05$ \\
\hline Complete thrombosis & $8(20.5)$ & & \\
\hline
\end{tabular}

Abbreviation: TEVAR, thoracic endovascular aortic repair. 
The study reported that the aortic remodeling rate (with TL re-expansion and thoracic FL thrombosis) was $91.3 \%$ in the TEVAR group, but only $19.4 \%$ with medical treatment alone $(P<0.001)$. However, according to the results in the follow-up period, no difference existed in regard to survival between the patients in the TEVAR group and those with medical management only. When it comes to the INSTEAD-XL trial, better aortic remodeling was observed after TEVAR in the longer follow-up, and favorable aortic remodeling was found to be associated with long-term survival in the TEVAR group, despite an early hazard. ${ }^{34}$ In addition, the trial revealed that re-intervention was rarely needed after primary TEVAR. In our study, the TEVAR+Cuff group had better TL recovery and FL shrinkage along with higher FL thrombosis in the thoracic and abdominal segments, albeit with no statistical difference when compared with the TEVAR group in the current follow-up. Meanwhile, slightly fewer adverse events occurred in the TEVAR+Cuff group $(P>0.05)$. We speculate that the difference will widen in further investigations.

There is no denying that a limitation of this study is the relatively short follow-up time. Meanwhile, it is our belief that there must be a perfect length of stent graft to prevent SCI and SIDR. Unfortunately, we did not manage to demonstrate it in this study.

\section{Conclusion}

TEVAR plus an aortic extender cuff placement for TBADs could reduce the incidence of SIDR by protecting the dissected aortic wall from the mechanical stress of the stent graft. The covered stent with a length of $250 \mathrm{~mm}$ would not increase the rate of paraplegia and is beneficial to aortic remodeling, thus reducing adverse events after endovascular repair, such as SIDR. However, longer-term clinical outcomes and continuous careful surveillance are urgently warranted to support these findings.

\section{Disclosure}

The authors report no conflicts of interest in this work.

\section{References}

1. Fattori R, Cao P, De Rango P, et al. Interdisciplinary expert consensus document on management of type B aortic dissection. J Am Coll Cardiol. 2013;61(16):1661-1678.

2. Coady MA, Ikonomidis JS, Cheung AT. Surgical management of descending thoracic aortic disease: open and endovascular approaches. a scientific statement from the American Heart Association. Circulation. 2010;121(25):2780-2804.

3. Pape LA, Awais M, Woznicki EM, et al. Presentation, Diagnosis, and Outcomes of Acute Aortic Dissection: 17-Year Trends From the International Registry of Acute Aortic Dissection. J Am Coll Cardiol. $2015 ; 66(4): 350-358$.
4. Dake MD, Kato N, Mitchell RS, et al. Endovascular stent-graft placement for the treatment of acute aortic dissection. $N$ Engl J Med. 1999;340(20):1546-1552.

5. Nienaber CA, Fattori R, Lund G, et al. Nonsurgical reconstruction of thoracic aortic dissection by stent-graft placement. $N$ Engl J Med. 1999;340(20):1539-1545.

6. Fattori R, Montgomery D, Lovato L, et al. Survival after endovascular therapy in patients with type B aortic dissection: a report from the International Registry of Acute Aortic Dissection (IRAD). JACC Cardiovasc Interv. 2013;6(8):876-882.

7. Durham CA, Cambria RP, Wang LJ, et al. The natural history of medically managed acute type B aortic dissection. J Vasc Surg. 2015; 61(5):1192-1199.

8. Erbel R, Aboyans V, Boileau C, et al. ESC Committee for Practice Guidelines. 2014 ESC Guidelines on the diagnosis and treatment of aortic diseases. Eur Heart J. 2014;35(41):2873-2926.

9. Andersen ND, Keenan JE, Ganapathi AM, Gaca JG, Mccann RL, Hughes GC. Current management and outcome of chronic type B aortic dissection: results with open and endovascular repair since the advent of thoracic endografting. Ann Cardiothorac Surg. 2014;3(3):264-274.

10. Patterson B, Holt P, Nienaber C, Cambria R, Fairman R, Thompson M. Aortic pathology determines midterm outcome after endovascular repair of the thoracic aorta: report from the Medtronic Thoracic Endovascular Registry (MOTHER) database. Circulation. 2013;127(1):24-32.

11. Dong Z, Fu W, Wang Y, et al. Stent graft-induced new entry after endovascular repair for Stanford type B aortic dissection. J Vasc Surg. 2010;52(6):1450-1457.

12. Xu SD, Huang FJ, du JH, et al. A study of aortic dimension in type B aortic dissection. Interact Cardiovasc Thorac Surg. 2008;7(2):244-248.

13. Feng J, Lu Q, Zhao Z, et al. Restrictive bare stent for prevention of stent graft-induced distal redissection after thoracic endovascular aortic repair for type B aortic dissection. J Vasc Surg. 2013;57(2):44S-52S.

14. He H, Yao K, Nie WP, et al. Modified Petticoat Technique with Preplacement of a Distal Bare Stent Improves Early Aortic Remodeling after Complicated Acute Stanford Type B Aortic Dissection. Eur J Vasc Endovasc Surg. 2015;50(4):450-459.

15. Xu SD, Huang FJ, Yang JF, et al. Endovascular repair of acute type B aortic dissection: early and mid-term results. J Vasc Surg. 2006; 43(6):1090-1095.

16. Neuhauser B, Greiner A, Jaschke W, Chemelli A, Fraedrich G. Serious complications following endovascular thoracic aortic stent-graft repair for type B dissection. Eur J Cardiothorac Surg. 2008;33(1):58-63.

17. Kpodonu J, Preventza O, Ramaiah VG, et al. Retrograde type A dissection after endovascular stenting of the descending thoracic aorta. Is the risk real? Eur J Cardiothorac Surg. 2008;33(6):1014-1018.

18. Kato N, Hirano T, Kawaguchi T, et al. Aneurysmal degeneration of the aorta after stent-graft repair of acute aortic dissection. J Vasc Surg. 2001;34(3):513-518.

19. Weng SH, Weng CF, Chen WY, et al. Reintervention for distal stent graft-induced new entry after endovascular repair with a stainless steelbased device in aortic dissection. J Vasc Surg. 2013;57(1):64-71.

20. Senf B, von Sachsen S, Neugebauer R, et al. The effect of stent graft oversizing on radial forces considering nitinol wire behavior and vessel characteristics. Med Eng Phys. 2014;36(11):1480-1486.

21. Feng J, Lu Q, Zhao Z, et al. Restrictive bare stent for prevention of stent graft-induced distal redissection after thoracic endovascular aortic repair for type B aortic dissection. J Vasc Surg. 2013;57 (2 Suppl):44S-52S.

22. Li Q, Wang LF, Ma WG, et al. Risk factors for distal stent graft-induced new entry following endovascular repair of type B aortic dissection. J Thorac Dis. 2015;7(11):1907-1916.

23. Riambau V, Böckler D, Brunkwall J, et al. Editor's Choice Management of Descending Thoracic Aorta Diseases: Clinical Practice Guidelines of the European Society for Vascular Surgery (ESVS). Eur J Vasc Endovasc Surg. 2017;53(1):4-52.

24. Ullery BW, Cheung AT, Fairman RM, et al. Risk factors, outcomes, and clinical manifestations of spinal cord ischemia following thoracic endovascular aortic repair. J Vasc Surg. 2011;54(3):677-684. 
25. Buth J, Harris PL, Hobo R, et al. Neurologic complications associated with endovascular repair of thoracic aortic pathology: Incidence and risk factors. A study from the European Collaborators on Stent/Graft Techniques for Aortic Aneurysm Repair (EUROSTAR) Registry. J Vasc Surg. 2007;46(6):1103-1111.

26. Drinkwater SL, Goebells A, Haydar A, et al. The incidence of spinal cord ischaemia following thoracic and thoracoabdominal aortic endovascular intervention. Eur J Vasc Endovasc Surg. 2010;40(6):729-735.

27. Uchida N. How to prevent spinal cord injury during endovascular repair of thoracic aortic disease. Gen Thorac Cardiovasc Surg. 2014; 62(7):391-397.

28. Hiraoka T, Komiya T, Tsuneyoshi H, Shimamoto T. Risk factors for spinal cord ischaemia after thoracic endovascular aortic repair. Interact Cardiovasc Thorac Surg. 2018;27(1):54-59.

29. Bisdas T, Panuccio G, Sugimoto M, Torsello G, Austermann M. Risk factors for spinal cord ischemia after endovascular repair of thoracoabdominal aortic aneurysms. J Vasc Surg. 2015;61(6):1408-1416.
30. Feezor RJ, Martin TD, Hess PJ, et al. Extent of aortic coverage and incidence of spinal cord ischemia after thoracic endovascular aneurysm repair. Ann Thorac Surg. 2008;86(6):1809-1814.

31. Amabile P, Grisoli D, Giorgi R, Bartoli JM, Piquet P. Incidence and determinants of spinal cord ischaemia in stent-graft repair of the thoracic aorta. Eur J Vasc Endovasc Surg. 2008;35(4):455-461.

32. Chiesa R, Melissano G, Marrocco-Trischitta MM, Civilini E, Setacci F. Spinal cord ischemia after elective stent-graft repair of the thoracic aorta. J Vasc Surg. 2005;42(1):11-17.

33. Nienaber CA. Influence and critique of the INSTEAD Trial (TEVAR versus medical treatment for uncomplicated type B aortic dissection). Semin Vasc Surg. 2011;24(3):167-171.

34. Nienaber CA, Kische S, Rousseau H, et al. Endovascular repair of type B aortic dissection: long-term results of the randomized investigation of stent grafts in aortic dissection trial. Circ Cardiovasc Interv. 2013;6(4):407-416.
Clinical Interventions in Aging

\section{Publish your work in this journal}

Clinical Interventions in Aging is an international, peer-reviewed journal focusing on evidence-based reports on the value or lack thereof of treatments intended to prevent or delay the onset of maladaptive correlates of aging in human beings. This journal is indexed on PubMed Central, MedLine,

\section{Dovepress}

CAS, Scopus and the Elsevier Bibliographic databases. The manuscript management system is completely online and includes a very quick and fair peer-review system, which is all easy to use. Visit http://www.dovepress. com/testimonials.php to read real quotes from published authors. 